\title{
Materialization of Regional Health Information Networks in Greece: Electronic Health Record Barriers \& Enablers
}

\author{
Dimitrios G. Katehakis, MS*, Stelios Halkiotis, PhD, Angelina Kouroubali, PhD \\ Institute of Computer Science, Foundation for Research and Technology - Hellas, \\ Heraklion, Crete, Greece
}

Submitted July 2010. Accepted for publication May 2011.

\begin{abstract}
This paper draws upon the experience of production level implementations, initiated through public procurement, of four regional health information networks (RHINs). The RHINs are being implemented in four regional health authorities (RHAs) in Greece to support patient-centred services. This paper focuses on three key areas: (i) engineering issues related to the deployment of an integrated electronic health record (EHR) system, (ii) management issues regarding implementation and planning, and (iii) socio-organizational issues influencing the outcome of large scale EHR implementations. The complexity of the health sector is also presented focusing on EHR barriers and enablers at institutional and regional levels. Reasons why EHR system implementations have not progressed as expected are also discussed.
\end{abstract}

Keywords: EHR, regional health information networks, organizational issues, EHR implementation, eHealth network, integrated healthcare delivery systems, EHR systems

\section{INTRODUCTION}

Electronic health (eHealth) services have the potential to improve access to healthcare and enhance the quality and effectiveness of health services. According to the Commission of the European Communities: "eHealth describes the application of information and communication technologies (ICT) across the whole range of functions that affect the health sector" [1], including products, systems for health authorities, professionals, as well as personalized health systems for patients and citizens. eHealth deployment introduces organisational changes and new skills to improve productivity and restructure health systems for citizen-centred services. Comparable and high-quality

Corresponding Author: Dimitrios G. Katehakis, Foundation for Research and Technology - Hellas, Institute of Computer Science, N. Plastira 100, Vassilika Vouton, GR-70013 Heraklion, Crete, Greece. Phone: +30 (2810) 391589, Fax: +30 (2810) 391496. Email: katehaki@ics.forth.gr. Other authors: halkioti@ics.forth.gr; kouroub@ics.forth.gr. 
administrative and clinical data form the basis for effective and efficient management of public and clinical health. Electronic health records (EHRs) and care flow management systems are tools that provide integrated and comprehensive data and have the capacity to transform clinical and business practices, content of work and information flows, in order to achieve cost reductions and quality of care improvements [2].

Factors that facilitate EHR implementations include performance feedback, continuous quality improvement, opinion leaders, communication networks, stakeholder involvement, a priori consideration of changes in professional practices and relations, communication of benefits to individuals and organizational groups, effective management of change, and advance knowledge of stakeholder perceptions [3-7]. However, taking these factors into consideration does not necessarily lead to successful implementations [8,9], unless the unique characteristics of implementation environments are considered in relation to these factors, and special attention is given to encouraging and facilitating change [10].

Evidence shows that eHealth implementations often do not meet initial project objectives for either private or public sectors [11-14]. Lorenzi and Riley point out that the two most important reasons for implementation failures are communication deficiencies and user ownership [15]. Hindering factors for eHealth implementations also include planning and design that does not account for the uniqueness of implementation environments [16, 17]. Other factors frequently reported in the literature for hindering implementations relate to resistance to change and negative attitudes of healthcare professionals [18].

In 2000, the Greek government, in accordance with the European Union recommendations for the Information Society, procured an operational program for implementing the information society strategy for Greece in a coherent and integrated way [19-21]. The program aimed to provide information technology (IT) support for regional health authorities (RHA) and their public health organizations, to achieve better management of human resources and performance, containment of total cost, and continuous improvement of processes. Foreseen benefits included an upgraded quality of services to citizens through business process reengineering and reduction of medical errors, secure exchange of medical information, and efficient access to the EHR.

Implementation of regional health information networks (RHINs) in Greece, a relatively recent endeavour, was guided by awareness of barriers and enabling factors as described in the literature and presented above. Organizational change, as a fundamental component of implementation efforts, was viewed as a continuous process that springs from within the organization based on collective and individual efforts. This paper presents a qualitative case study regarding four RHIN implementations in Greece. The research objectives include an analysis of the complexity regarding RHIN implementation and the identification of facilitating and inhibiting factors related to engineering, social and organizational issues. The research focuses on the implementation of patient administration and medical applications. Analysis of policy and legislation of the Greek public sector is beyond the scope of this paper.

The remaining contents of the paper are organized as follows: Section 2 provides a description of the Greek RHIN initiative and the methodology for data collection and 
analysis. Section 3, Research Results, describes issues encountered during implementations and the approaches taken to address the challenges. Section 4 discusses research results, while Section 5 concludes with insights related to RHIN development, success factors, and challenges.

\section{METHODS}

Since 1994, Foundation for Research and Technology - Hellas, referred to in the rest of the paper as the Research Center, has been preparing the ground for wide scale RHIN implementations through the development of HYGEIAnet, the first integrated health telematics network in Greece, on the island of Crete [22-25]. The implementation of HYGEIAnet was instrumental for the Research Center to gain significant knowledge and experience in RHIN implementations. Today, the Research Center, as a member of consortiums, is in the process of completing the implementation of four national projects for the delivery of integrated health information systems and ICT services for four RHAs, sharing similar characteristics in terms of organization and delivery of healthcare services. The number of healthcare organizations and population size of each RHA involved in implementations is presented in Table 1. Authority names are disguised to secure confidentiality.

RHINS in the four RHAs involved both enterprise and cross-enterprise applications, as described in Table 2 and Table 3 - note that Research Center's applications are underlined. The Research Center delivered patient administration and medical applications, the primary care centre information system, the integrated booking service, health information infrastructure (HII) components and the integrated electronic health record (I-EHR) [26]. Also, the Research Center was responsible for message brokering, central patient registry, and interoperability of its applications and services with enterprise resource planning (ERP), laboratory information system (LIS), and management information system (MIS).

In order to explore the dynamic processes and understand the complexity of EHR implementation efforts, the four RHIN implementations in Greece were examined as a case study. The projects were closely monitored for progress and outcomes. Data collection was qualitative [28] and involved document review, participatory observations, and interviews with key stakeholders. During data analysis, important themes were identified and compared across regions. Case study analysis investigated the factors that influenced eHealth implementations, identified good practices and offer recommendations for similar initiatives in Greece and elsewhere. Data collection

Table 1. RHA characteristics

\begin{tabular}{cccc}
\hline RHA & Hospitals & Primary Care Centers & Population \\
\hline A & 10 & - & $\sim 2,700,000$ \\
B & 4 & 13 & $\sim 200,000$ \\
C & 8 & 6 & $\sim 700,000$ \\
D & 6 & 5 & $\sim 700,000$ \\
\hline
\end{tabular}


Table 2. Enterprise applications developed for the RHAs

\begin{tabular}{|c|c|}
\hline Application & Description \\
\hline ERP & $\begin{array}{l}\text { Incorporates costing, general ledger, analytical accounting, } \\
\text { budgeting, payable accounts, receivable accounts, human } \\
\text { resources management, assets management, materials } \\
\text { management, supply chain management, funds } \\
\text { management, contract management, etc. }\end{array}$ \\
\hline Patient administration* & $\begin{array}{l}\text { Applications for patient management such as admissions, } \\
\text { discharge, transfers, bookings, accounts, etc., within the } \\
\text { involved, regional healthcare organizations. }\end{array}$ \\
\hline Medical applications & $\begin{array}{l}\text { Support all healthcare organization processes related to the } \\
\text { provision of medical and nursing care for outpatient clinics, } \\
\text { emergency rooms, diagnostic procedures, medical } \\
\text { documentation, doctor letters, medical history, order entry } \\
\text { management, nursing stations, etc. }\end{array}$ \\
\hline LIS & $\begin{array}{l}\text { Supports non-imaging laboratories and incorporates all } \\
\text { related business rules and interfaces with laboratory } \\
\text { devices. }\end{array}$ \\
\hline MIS & $\begin{array}{l}\text { Includes data analysis in regard to patient admission and } \\
\text { discharge (e.g. hospital workload, etc.), financial analysis } \\
\text { (e.g. mean hospitalization cost, mean examination cost, } \\
\text { financial projections, etc.), and human recourses (e.g. } \\
\text { vacancies in healthcare organizations, variations in staffing, } \\
\text { personnel productivity, etc.). }\end{array}$ \\
\hline $\begin{array}{l}\text { Primary care centre } \\
\text { information system }\end{array}$ & $\begin{array}{l}\text { Supports the electronic storage and management of patient } \\
\text { data, regarding visits to primary care providers. }\end{array}$ \\
\hline
\end{tabular}

*Research Center's applications are underlined.

particularly focused on stakeholder interaction, information exchange, good practices and instances of change. Factors that influence eHealth implementations, as described in the literature, were used as the basis to identify similar factors and themes in the case study. Literature review of concepts, factors, recommendations and themes of eHealth implementations formed the methodological foundation for data collection and analysis.

\section{RESULTS}

In complex systems, there are many ways to realize a particular goal. Hence, predicting precise user strategies to achieve a task becomes difficult and even impossible for designers [29]. Additional complexity is created when multiple systems from different vendors need to be integrated. Complexity of healthcare systems also relates to continuous change in structure, goals and values [30]. The following sections describe the implementation experiences and lessons learned in the complex environment of Greek public health sector. 
Table 3. Cross-enterprise applications developed for the RHAs

\begin{tabular}{ll}
\hline Application & Description \\
\hline Central patient registry* & $\begin{array}{l}\text { Accessed by all patient administration applications, } \\
\text { assigning unique patient identifiers within the RHA } \\
\text { boundaries. } \\
\text { Consolidated MIS for the needs of the RHA, incorporating } \\
\text { information from all healthcare organizations. } \\
\text { Acts as a common communication point for the RHA and } \\
\text { RHA portal } \\
\text { supports online appointment booking to selected healthcare } \\
\text { organizations for the majority of the RHAs, without } \\
\text { providing online access to EHRs. } \\
\text { For all departments and healthcare organizations within a } \\
\text { region, for the majority of the RHAs. } \\
\text { Supports sharing of EHR information across healthcare } \\
\text { organizations. The federated integrated care EHR approach } \\
\text { has been selected by Research Center over the consolidated } \\
\text { one [27] due to the need for operational independence for } \\
\text { time critical operations among healthcare organizations. }\end{array}$ \\
\hline
\end{tabular}

*Research Center's applications are underlined.

\subsection{Engineering Issues}

RHINs are very complex systems requiring an architectural framework to set the basis for independence as well as cooperation [31-33]. Independence of system aspects is required to enable multiple sources of solution parts. Cooperation between these otherwise independent aspects is essential in any non-trivial architecture. In this context, the architecture of the four RHINs provided and enabled interoperability, modularity (so that the infrastructure can be assembled piece by piece), migration (so that pieces that are out-dated can be replaced with new ones), stability (through maintenance), and cost-effectiveness by leveraging main stream technologies and products.

All applications and services of the four RHINs positioned EHR at the core as depicted in Figure 1. All applications, services and communication with external systems and entities were built around the EHR, based on a common software and hardware infrastructure. Training, installation and support were offered across applications.

The issue of data exchange between healthcare units at a regional level has been handled by three alternative approaches: (i) through the exchange of health level seven (HL7) messages addressing specific interoperability scenarios [34], (ii) through access to HII components enabling integration, both within the region as well as with external entities like suppliers, insurance companies, and the ministry of health and social solidarity, and (iii) through the MIS.

In order to handle complexity imposed when trying to integrate systems from different vendors, all interfaces defined (both standardized and proprietary) were based 


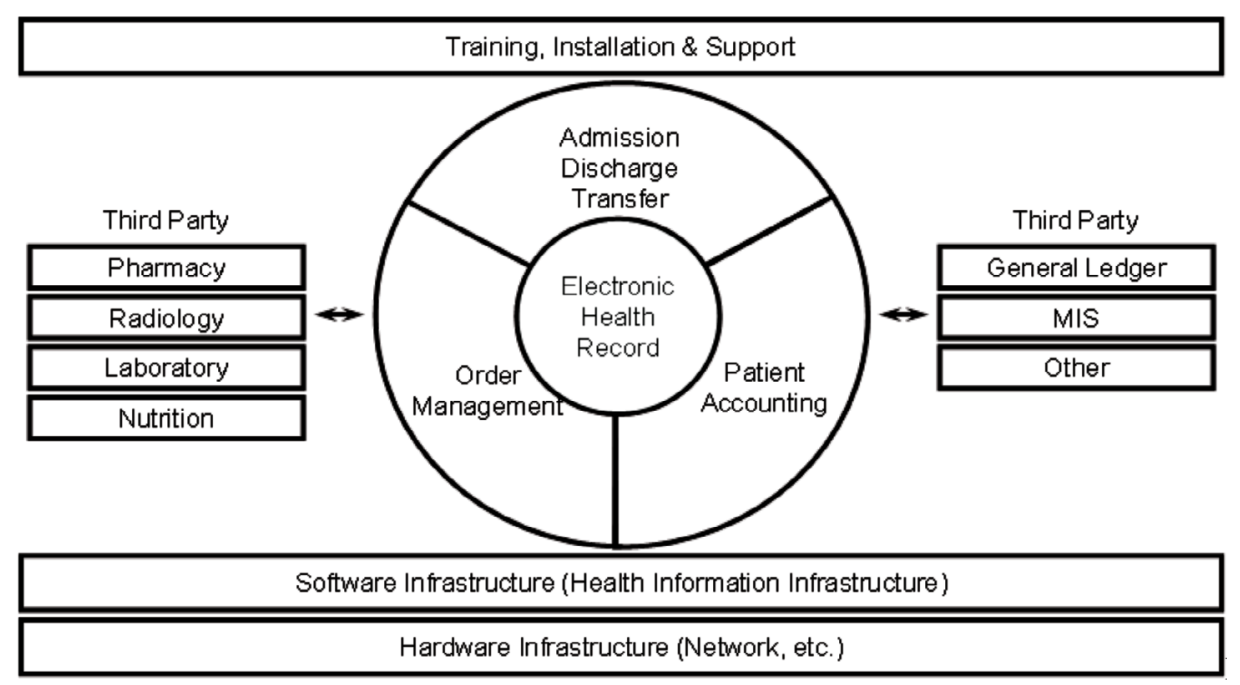

Figure 1. Architectural approach is structured around a citizen-centred EHR

on a common domain model, different for each of the four RHAs, based on a standardized reference model, and a corresponding controlled common vocabulary. Subsequently, part of the schema of each information system participating in the federation was mapped to that particular, common for each region, normalized schema. Unified management of codification for each RHA was a mandatory requirement.

Security was another important requirement of great concern. To address this requirement, each RHIN included a complete risk assessment study and a security operation plan. Security strategy was developed by the RHA, the technical consultant, and partly the final contractor who was responsible for its implementation. Data entry stations featured applications with role-based access control accessible to authorized users only. Usernames and passwords were used to access the applications and a lockupon-inactivity function was implemented. Single sign-on was supported and the overall infrastructure was managed largely through SYZEFXIS [35], the public administration network of Greece, in line with national legislation and European directives.

All the applications were purchased by the contracting authorities as commercial offthe-shelf products. The Research Center started initially with a common solution for all regions; however, significant software development followed. No public hospital or primary care centre shared the same operational procedures, codification processes, calculation methods for statistical data, or presentation of documents and forms. Modularity and adaptability of the technical solution, based on international standards and guidelines, allowed the Research Center to address regional and institutional requirements with minimal cost. However, this endeavour required extra time and effort that was usually not factored in the initial contracts.

It is important to note that double entry of EHRs occurred as an issue soon after data migration. This issue was encountered because not all citizens were recognized by means 
of a unique identifier in their contacts with health services. The political decision to use the social security number (AMKA) as the unique patient identifier within regions, was taken by the Greek government in 2009. However, no provision was taken for legacy data that did not have an AMKA number associated with it. As a result, the Research Center was not in a position to make the field for the unique identifier - now in use - a mandatory field in its products. Actions are still required, at a regional level, in order to clean the central patient registry from duplicate entries, without affecting available hospital data.

\subsection{Implementation Progress}

Each RHIN implementation consisted roughly of five phases (listed in Table 4). In practice, phases overlapped, and after successful completion of pilot operations, they were split to parallel activities depending on the healthcare organizations involved.

Phase 1 involved on site visits to healthcare organizations, documentation of existing organizational processes, software, culture, and needs. Established aspects at this stage

Table 4. RHIN implementation: foreseen vs. actual duration (in months), as of September 2010

\begin{tabular}{|c|c|c|c|c|}
\hline \multirow[b]{2}{*}{ Phase } & \multicolumn{4}{|c|}{$\begin{array}{l}\text { RHA implementation time, } \\
\text { foreseen/actual (in months) }\end{array}$} \\
\hline & A & B & C & D \\
\hline $\begin{array}{l}\text { 1: Feasibility study } \\
\text { (from the signing of the } \\
\text { contract until the approval } \\
\text { of the study) }\end{array}$ & $\begin{array}{c}4 / 9 \\
\text { (completed) }\end{array}$ & $\begin{array}{c}3 / 4 \\
\text { (completed) }\end{array}$ & $\begin{array}{c}3 / 9.5 \\
\text { (completed) }\end{array}$ & $\begin{array}{c}3 / 6 \\
\text { (completed) }\end{array}$ \\
\hline $\begin{array}{l}\text { 2: Procurement and } \\
\text { acceptance tests } \\
\text { (from the approval of the } \\
\text { study until approval for } \\
\text { the pilot site to go live) }\end{array}$ & $\begin{array}{c}7 / 14 \\
\text { (completed) }\end{array}$ & $\begin{array}{c}9 / 20 \\
\text { (completed) }\end{array}$ & $\begin{array}{c}9 / 24 \\
\text { (completed) }\end{array}$ & $\begin{array}{c}8 / 16 \\
\text { (completed) }\end{array}$ \\
\hline $\begin{array}{l}\text { 3: Pilot operation } \\
\text { (from approval for the } \\
\text { pilot site to go live } \\
\text { until its certification) }\end{array}$ & $\begin{array}{c}2 / 14 \\
\text { (completed) }\end{array}$ & $\begin{array}{c}2 / 7 \\
\text { (completed) }\end{array}$ & $\begin{array}{c}2 / 4 \\
\text { (completed) }\end{array}$ & $\begin{array}{c}1 / 13 \\
\text { (completed) }\end{array}$ \\
\hline $\begin{array}{l}\text { 4: Training and roll-out } \\
\text { (from certification of the } \\
\text { pilot site until the certification } \\
\text { of the last organization) }\end{array}$ & $\begin{array}{c}4 / 0 \\
\text { (completed) }\end{array}$ & $\begin{array}{c}4 / 21 \\
\text { (pending) }\end{array}$ & $\begin{array}{c}4 / 11 \\
\text { (completed) }\end{array}$ & $\begin{array}{c}4 / 22 \\
\text { (pending) }\end{array}$ \\
\hline $\begin{array}{l}\text { 5: Maintenance \& support services } \\
\text { (from certification of the last } \\
\text { organization until the official } \\
\text { completion of the project) }\end{array}$ & $\begin{array}{c}6 / 10 \\
\text { (pending) }\end{array}$ & $\begin{array}{c}12 /- \\
\text { (pending) }\end{array}$ & $\begin{array}{c}12 / 1 \\
\text { (completed) }\end{array}$ & $\begin{array}{c}14 /- \\
\text { (pending) }\end{array}$ \\
\hline
\end{tabular}


involved degree of utilization of existing equipment \& infrastructure, final architecture, scope and prioritization of user requirements, interoperability guidelines, codification, data migration and training plan. End users were heavily involved during this phase. Phase 2 involved installation of hardware, software and acceptance tests. Acceptance tests of applications and services involved end users, technical consultants and representatives from the contracting authorities. Phase 3 involved application customization, user training and initiation of productive operations for applications and services in a carefully selected site. The pilot site was usually a typical, medium-size organization, where all user application scenarios could be tested in production conditions. Phase 4 involved training and roll out to the remaining healthcare organizations of each region. Modification of time plans was required to include maintenance and support for certified organizations (i.e., organizations where full scale deployment had been completed). Training was provided to all personnel. In certain cases, on the job training was provided during shifts, however, not during all shifts. Finally, phase 5 involved technical support, on the job training, helpdesk services, and a service level agreement for guaranteed level support, which was initiated following each healthcare organization's certification. For all healthcare organizations in phase 5, 24/7 support was provided.

All RHINs and healthcare organizations shared similar characteristics and requirements. However, each RHIN implementation was different and each healthcare organization unique. For all projects, implementation time was underestimated and both successful and less successful practices were observed. Table 5 presents implementation status for each project, as of September 2010.

Project A met significant difficulties and delays at its initial stages of implementation. However, implementations accelerated after completion of acceptance tests. Eight hospitals were up and running in the first seven months of 2009. The remaining two hospitals managed to operate only human resource management. This

Table 5. RHIN implementation status

\begin{tabular}{|c|c|c|c|c|c|}
\hline RHA & $\begin{array}{l}\text { Start } \\
\text { Date }\end{array}$ & Project Duration & $\begin{array}{l}\text { Hospitals } \\
\text { Involved }\end{array}$ & $\begin{array}{c}\text { In Operation } \\
\text { (at least one RHIN } \\
\text { application } \\
\text { operational) }\end{array}$ & $\begin{array}{c}\text { Certified } \\
\text { (full scale } \\
\text { deployment } \\
\text { completed }\end{array}$ \\
\hline A & $11 / 2006$ & $\begin{array}{c}24 \text { months } \\
\text { (extended to } 47 \text { ) }\end{array}$ & 10 & 10 & 10 \\
\hline B & $5 / 2006$ & $\begin{array}{c}30 \text { months } \\
\text { (extended to } 43 \text {, } \\
\text { new extension pending) }\end{array}$ & 4 & 3 & 2 \\
\hline $\mathrm{C}$ & $10 / 2005$ & $\begin{array}{c}30 \text { months } \\
\text { (extended to } 49.5 \text { ) } \\
30 \text { months }\end{array}$ & 8 & 8 & 8 \\
\hline D & $12 / 2005$ & $\begin{array}{c}\text { (extended to } 47 \\
\text { new extension pending) }\end{array}$ & 6 & 6 & 3 \\
\hline
\end{tabular}


occurred because of the special legal status of one hospital, allowing limited RHA control over it. According to stakeholder interviews, the second hospital failed because management was not willing to go against staff resistance and implement the necessary organizational changes. Although all hospitals were certified, and maintenance and support services were delivered in 2009 , the project was expected to conclude at the end of 2010, due to bureaucracy reasons.

In region B two out of four hospitals were certified. The implementation of the RHIN was challenging because accessibility to the majority of the sites was difficult due to their geographical dispersion. The pilot ran for 15 days and then stopped, mainly due to the strong resistance met from the hospital's supply chain management department. Nine months later, the pilot was completed successfully in another, much less organized, hospital. Main issues encountered related to syndicalism of hospital employees, political conflict with the ruling government, and lack of qualified personnel. The training and roll-out phase of the project is currently under suspension as the new government is seeking funds for the project's completion.

In project $\mathrm{C}$, the contractual authority demonstrated strong commitment and provided efficient, robust management. However, not all stakeholders showed the same level of readiness to respond, resulting in significant delays. The project was completed in 49.5 months instead of the originally planned 30 months. Difficulties were overcome with the direct involvement of top and middle management.

Project D presented the greatest difficulties. The regional data centre had to be relocated three times. The biggest hospital in the region put forth many non-contractual, expensive to implement demands as pre-conditions for going live. The second biggest hospital in the region suffered severe damages from a catastrophic earthquake in June 2008. A third hospital has not been certified due to its managerial disputes with the RHA, not allowing full deployment of RHIN applications. Record keeping in that particular hospital is still done by means of spread sheets. Phase 4 of the project, training and roll-out, is currently under suspension, and the new government is seeking funds for its completion.

\subsection{Management and Socio-Organizational Issues}

Implementation practices involved visits to all health care organizations to map the location of rooms and workstations, several interviews with personnel of hospital departments to identify document exchange and business processes, and discussions in workshops of user groups appointed by the RHA. Customization occurred in all projects based on differences of procedures at the hospital and regional levels.

Even though key representatives of healthcare organizations, including end users, participated throughout the lifespan of each project including design, evaluation, management, and operation, user involvement was not enough to lead to successful implementations. Implementations required adaptability, readiness to respond to uncertainty and ability to create proper conditions for installation and use of services. Awareness of the particular dynamics within each RHA and its healthcare organizations was especially crucial. Assigning the appropriate team of implementers for each hospital, identifying the appropriate way for making the first contact with a hospital, 
and deciding on a realistic and feasible timeline were instrumental for successful implementations. Growing experience allowed the Research Center to identify attitudes that acted as facilitators or barriers to implementations.

Observations focused on wants and needs of end-users, but also on general negative or indifferent attitudes. Once the problem was observed, it was easier to find a solution in collaboration with the hospital manager the contracting authority, or the RHA. Usually, deadlocks were overcome either by allowing extra time or by changing key personnel. Resistance and negativity were often valuable in providing information about problems and issues, and giving important feedback to the Research Center. Indifference was harder to handle. In general, it was observed that having hospital managers or regional authority directors replaced facilitated implementations. RHIN implementations supported by users could not be inhibited by newly appointed managers due to the high economic and political cost. The ability to be patient and wait for the right moment to act, proved to be very important.

Technical requirements in the four RHINs were neither detailed, nor fixed. Although a general requirement outline was provided, requirements changed among RHINs and within individual healthcare organizations. Flexibility and patience, again, turned out to be virtues and critical enablers for successful implementation. Careful mapping of internal procedures and anticipation of changes upon the introduction of the system, were also essential. However, this was also a great challenge as most business processes and operations were informal.

While RHINs were being implemented, the number of RHAs was reduced from 17 to 7. That meant that in each RHA, the area and population of responsibility became larger, and more than one RHIN were under implementation in one region. Integration of the regions did not account for integration and interoperability of the different RHINs. In addition, even though all RHIN projects were supported by the government, some hospitals did not take the effort seriously and failed to deliver basic prerequisites for the proper operation of the RHIN. As a result, one hospital had to go live without having the required network infrastructure, migration of data, or personnel training in system functionalities. Determination of RHA and the contractor allowed the incorporation of this hospital to the RHIN, avoiding collapse during the initial weeks of productive operation. Changes were enforced violently making it clear that indifference is not tolerated and there is no alternative but to deliver the required migration data. Personnel received on the job training and all the necessary corrections to the network infrastructure were made under tremendous pressure.

Experience and best practices were communicated among key users within and across RHAs, facilitating the spread of implementations. Critical mass of users was created that pushed implementations forward. RHAs also played a crucial role in disseminating information about the progress of implementations.

Additional data entry and time was required in order to complete communication and integration among subsystems. Several added functionalities such as the possibility to extract statistical data, required recording additional information. End users often complained that the new graphical user interfaces were not user friendly requiring additional operations to complete a task. These complaints were often masking a 
reluctance to use a system that provided more information especially since managers took implementations as an opportunity to collect more data. Users were often afraid of being audited daily by their supervisors with the newly introduced functionalities of better and more detailed reporting, including business intelligence.

Gradually, as the system was fully integrated in daily operations, benefits started to become apparent. RHIN applications delivered forms with richer information than previously available. End users became aware that their effort went beyond their own department and affected other departments, creating a sense of integration which was previously missing. For example, with the new system, nursing staff performed online ordering and, as a result, data entry was significantly reduced in the pharmacy department. Overall, the workload was redistributed and eventually got balanced among different departments. Departments that benefited most from the system, such as the hospital pharmacy, embraced it. New ways of working created a critical mass of users with new mentality, making it harder to revert to old ways.

The existence of a service level agreement for guaranteed quality of services between the RHA and the consortium implementing the RHIN was important to offer users the possibility to call the helpdesk when assistance was required. This way, the hospital continued its uninterrupted operations and the users felt supported. Even though support for daily hospital operations was not included in the scope of work and project budget, it was required in some cases. This opportunity was not continued due to lack of resources and political will, placing sustainability of the whole effort at risk. In retrospect, this should be factored in the project budget because it is part of the complexity that characterizes implementation endeavours.

Finally, the fact that cross-departmental operations were not clearly conceived by end users led to several inconsistencies requiring technical interventions at subsystem interfaces. However, technical issues, although complex, did not present a critical obstacle.

\section{DISCUSSION}

Regional health care networks are important aspects of healthcare services to achieve cooperation of different institutions and professional groups in a common effort to deliver best quality service and cost-effective care [36]. Understanding organizational processes, context, and social interactions is essential for the design and implementation of effective information systems aimed for complex, dynamic organizations [37]. Partitioning of complex systems like RHINs to isolate functionality during the design process facilitates development, maintenance, modifications and upgrades [38]. Functions that change rapidly or evolve over time can be upgraded and changed with minor impact to the remainder of the system. The modular approach of addressing engineering issues proved particularly useful in the cases examined as it allowed a common engineering solution customizable for each healthcare institution. Meaningful exchange of information both within and across RHINs required an EHR reference model, common vocabularies, although proprietary in most of the cases, and standardized service interface models (e.g., by means of HL7 for intra-hospital communication). Semantic interoperability at this stage was not achieved at the EHR level due to lack of a standardized set of domain-specific concept. 
Even though all implementations examined in this paper involved similar public health care institutions, each one proved to be different. Previous experience with developing HYGEIAnet [39, 40] helped the Research Center in expecting the unexpected and be prepared for surprises. As implementations progressed, experience and insight made it easier to adapt to differences and overcome obstacles. The importance of awareness, adaptability and readiness to react to uncertainty was reinforced. Despite prerequisites and formal feasibility studies, traditional analytic approaches proved only partly responsible for successful implementations within the complex and dynamic environment of the case study.

Research has shown that several factors act as barriers to successful implementations [41]. Awareness of these factors and flexibility to consider each factor within the particular implementation context plays a crucial role to the success of implementations. For example, several implementations fail because physicians or other important groups are not included in the planning phases of implementations [42]. In the case of Greece, even though key stakeholders were involved throughout the project, their involvement was not considered very influential. The initial stage of change and uncertainty had to be overcome successfully in order to complete implementations and allow the EHR to demonstrate its potential. Assimilation time was required in order to reach equilibrium, following the turbulence of going live. Unfortunately lack of personnel and job descriptions were issues that could not be overcome and need to be addressed at the ministry level.

No matter how good the technical platform is, its selection is only part of the solution. All RHIN implementations, like those described in this paper, should expect to face short-term productivity losses. Determination to resolve obstacles through strong political support requires political alliance with regional bodies, and the appropriate legal and regulatory framework. The most difficult factor, the human factor, requires awareness and adaptation, together with deep knowledge of the domain. The most successful implementation processes appear to be those in which the obsession for control and planning is replaced by experimentation and mutual learning.

Realizing the full potential of EHR systems to contribute to improvements in clinical care and efficiency could take organizations 5 to 10 years. Strong executive and clinical leadership at all levels of the organization are needed for EHR implementation projects to be successful. Throughout the process, regional or national authorities, end users and technology providers are transformed through mutually influencing each other. If this is foreseen, such implementations can be strategically intended to help transform the involved entities. Awareness of enabling factors and barriers prior to and during implementation, flexibility and adaptability to address these factors, and the ability to respond to uncertainty are important qualities for successful implementation of RHINs.

\section{CONCLUSIONS}

In this paper, a qualitative case study regarding four RHIN implementations in Greece is presented. The research objectives include an analysis of the complexity regarding RHIN implementation and identification of facilitating and inhibiting factors related to engineering, social and organizational issues. The case study demonstrates that RHIN 
implementations in Greece share similar characteristics with large scale EHR implementations throughout Europe [43, 44]. The successful implementation of any RHIN to provide IT support for the RHA requires solution to a long list of technical, managerial, and organizational issues. An open architecture must be in place, together with the corresponding HII to successfully manage interoperability challenges, especially at an inter-enterprise level. Implementation must be carefully coordinated and properly planned for the production of outcomes acceptable by the stakeholders involved. Organizational issues must be considered carefully, and the appropriate political support must be in place to decisively resolve outstanding issues. In the process, all stakeholders influence and mutually transform each other in their effort to accommodate new practices, and address local and regional needs.

\section{CONFLICT OF INTEREST: None.}

\section{REFERENCES}

[1] Commission of the European Communities, e-Health - making healthcare better for European citizens: An action plan for a European e-Health Area, Communication from the Commision to the Council, The European Parliament, The European Economic and Social Committee and the Committee of the Regions, COM 356 final, 2004.

[2] National Committee for Quality Health Care, CEO survival guide(tm) to electronic health record systems, National Quality Forum, 2006.

[3] Anderson, J. G., Clearing the way for physicians' use of clinical information systems, Communications of the ACM, 1997, 40(8), 83-90.

[4] Ash, J.S., Bates, D.W., Factors and forces affecting EHR system adoption: Report of a 2004 ACMI discussion, Journal of the American Medical Informatics Association, 2005, 12 (1), 8-12.

[5] Lorenzi, N. M., Riley, R. T., et al., Antecedents of the people and organizational aspects of medical informatics: Review of the literature, Journal of the American Medical Informatics Association, 1997, 4 (2), 79-93.

[6] Ash, J.S., Gorman, P.N., Seshadri, V., Hersh, W.R., Perspectives on CPOE and Patient Care Information Systems: Research Paper: Computerized Physician Order Entry in U.S. Hospitals: Results of a 2002 Survey, JAMIA 2004, 11, 95-99

[7] Fenton, S. H., Giannangel,o K., Stanfill, M., Essential people skills for EHR implementation success, Journal of AHIMA, 2006, 77 (6), 60A-60D.

[8] Gruber, D., Cummings, G. G., Leblanc, L., \& Smith, D. L., Factors influencing outcomes of clinical information systems implementation: A systematic review, CIN - Computers Informatics Nursing, 2009, 27(3), 151-163.

[9] Poulymenakou, A., Holmes, A., A contingency framework for the investigation of information systems failure, European Journal of Information Systems, 5 (1), 1996, 34-47.

[10] Ludwick, D. A., Doucette, J., Adopting electronic medical records in primary care: Lessons learned from health information systems implementation experience in seven countries, International Journal of Medical Informatics, 2009, 78(1), 22-31.

[11] Van Der Meijden, M. J., Tange, H.J., et al., Determinants of success of inpatient clinical information systems: A literature review, Journal of the American Medical Informatics Association, 2003, 10 (3), pp. 235-243.

[12] Lorenzi, N. M., Novak, L. L., et al., Crossing the implementation chasm: A proposal for bold action, Journal of the American Medical Informatics Association, 2008, 15(3), 290-296.

[13] Brown, S. A., Chervany, N. L., et al., What matters when introducing new information technology, Communications of the ACM, 2007, 50 (9), 91-96. 
[14] Heeks, R., Health information systems: Failure, success, and improvisation, International Journal of Medical Informatics, 2006, 75, 125-137.

[15] Lorenzi, N. M., Riley, R. T., Managing Change: An Overview, Journal of the American Medical Informatics Association, 2000, 7, 116-24.

[16] Westrup, C., What's in information technology?, Implementation and evaluation of information systems in developing countries, eds. C. Avgerou, Asian Institute of Technology, 1998, 77-91.

[17] Heeks, R., Mundy, D., Salazar, A., Understanding success and failure of health care information systems, in A. Armoni (ed) Healthcare Information Systems: Challenges of the New Millennium, Idea Group Publishing, USA, 2000, 96-128.

[18] Dansky, K. H., Gamm, L. D., et al., Electronic medical records: Are physicians ready?, Journal of Healthcare Management, 1999, 44 (6), 440-455.

[19] Greece in the Information Society, Strategy and Actions, 1 February 1999, http://www.epractice.eu/ node/281163 [accessed December 6, 2010].

[20] Greece in the Information Society, Strategy and Actions, 24 January 2002, http://www.epractice.eu/ en/library/281110 [accessed December 6, 2010].

[21] Operational Programme "Information Society" (REGIO/2001/00227-00-00), http://www.infosoc.gr/ NR/rdonlyres/2A49C506-BF24-46D0-A933-1CD3B122F389/409/InformationSociety_program.doc [accessed December 6, 2010].

[22] Katehakis, D. G., Tsiknakis, M., and Orphanoudakis, S. C., Enabling components of HYGEIAnet, Proceedings of the 17th Annual Towards an Electronic Patient Record Conference and Exhibition (TEPR 2001), Your Connection to Electronic Healthcare, Boston, Massachusetts, USA, 2001, $146-153$.

[23] Tsiknakis, M., Chronaki, C. E., Kostomanolakis, S., and Orphanoudakis, S. C., The regional health telematics system of Crete, Proceedings of the Health Telematics ' 95 Conference, Naples, Italy, 1995, $553-558$.

[24] Kouroubali, A., Sakkalis, V., Chronaki, C. E., and Tsiknakis, M., eChallenges in the implementation of eHealth services over a hybrid network architecture: The case of eLearning, Exploiting the Knowledge Economy: Issues, Applications and Case Studies, IOS Press, 3, 2006, 997-1004.

[25] eHealth 2003 High Level Conference, http://ec.europa.eu/information_society/eeurope/ehealth/ conference/2003/index_en.htm [accessed December 6, 2010].

[26] Katehakis, D. G., Sfakianakis, S. G., Anthoulakis, D., Kavlentakis, G., Tzelepis, T. Z., Orphanoudakis, S. C., Tsiknakis, M., A holistic approach for the delivery of the integrated electronic health record within a regional health information network, FORTH-ICS/ TR-350, 2005, http://www.ics.forth.gr/ $\sim$ katehaki/publications/tr350.pdf [accessed December 6, 2010].

[27] ISO/TR 20514:2005, Health informatics, Electronic health record, definition, scope and context.

[28] Miles, M., Huberman A., Qualitative data analysis, London, Sage, 1994.

[29] Effken, J. A., Different lenses, improved outcomes: a new approach to the analysis and design of health information systems, International Journal of Medical Informatics, 2002, 65, 59-74.

[30] Wheatley, M. J., Leadership and the new science: Learning about organization from an orderly universe, Berrett-Kohler, San Francisco, 1992.

[31] Tsiknakis, M., Katehakis, D. G., Orphanoudakis, S. C., An Open, Component-based information infrastructure for integrated health information networks, International Journal of Medical Informatics, 2002, 68 (1-3), 3-26.

[32] Constantinides, P., Barrett, M., Large-scale ICT innovation, power, and organizational change, The Journal of Applied Behavioral Science, 2006, 42 (1), 76-90.

[33] Mäenpääa, T., Suominena, T., Asikainen, P., Maass, M. and Rostila, I., The outcomes of regional healthcare information systems in health care: A review of the research literature, International Journal of Medical Informatics, 2009, 78 (11), 757-771.

[34] Health Level Seven, http://www.hl7.org [accessed December 6, 2010]. 
[35] SYZEFXIS National Public Administration Network, http://www.syzefxis.gov.gr [accessed December $6,2010]$.

[36] Oates, J. and Jensen, B. H. (eds), Building Regional Health Care Networks in Europe, Studies in Health Technology and Informatics, Vol 67, IOS press Amsterdam, 2000.

[37] Lorenzi, N. M., Kouroubali, A., Detmer, D. E., Bloomrosen, M., How to successfully select and implement electronic health records (EHR) in small ambulatory practice settings, BMC Medical Informatics \& Decision Making, 2009, 9 (15), http://www.biomedcentral.com/1472-6947/9/15 [accessed December 6, 2010].

[38] Katehakis, D. G., The PICNIC Story, Regional Health Economies and ICT Services: The PICNIC Experience, IOS Press, Volume 115 Studies in Health Technology and Informatics, 2005, 4-36.

[39] Tsiknakis, M., Kouroubali, A., Organizational factors affecting successful adoption of innovative eHealth services: a case study employing the FITT framework, International Journal of Medical Informatics, 2009, 78 (1), 39-52.

[40] Kouroubali, A., Detmer, D.E., Tsiknakis, M., Orphanoudakis, S. A., Health Care Information System in Greece: Key Factors, Self-Organization and Take-Home Lessons in Understanding Health Communications Technologies: A Case Study Approach, eds Whitten, P., Cook, D., Jossey-Bass, San Francisco, 2004, 69-79.

[41] Scott, J. T., Rundall, T. G., Vogt, T. M., Hsu, J., Kaiser Permanente's Experience of Implementing an Electronic Medical Record: A Qualitative Study, BMJ, 2005, 331 (7528), 1313-1316.

[42] Kaplan, B., Addressing organizational issues into the evaluation of medical systems, Journal of the American Medical Informatics Association, 4, 1997, 94-101.

[43] Berg, M., Implementing information systems in health care, organizations: Myths and challenges, International Journal of Medical Informatics, 2001, 64 (2-3), 143-56.

[44] Esterle, L., Kouroubali, A., Political and organisational factors influencing large scale implementation of electronic health records: Recommendations for a Realistic Implementation Plan, EHR-Implement project, 2010, http://www.ehr-implement.eu [accessed December, 6, 2010]. 



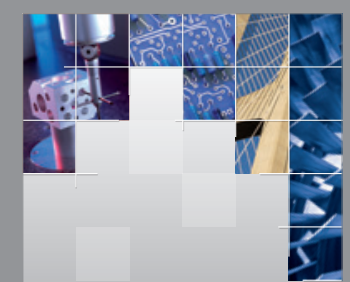

\section{Enfincering}
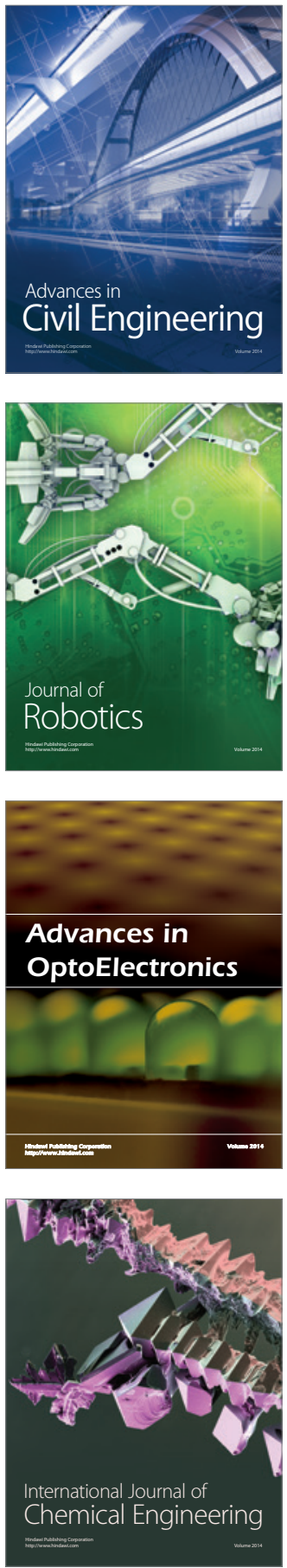

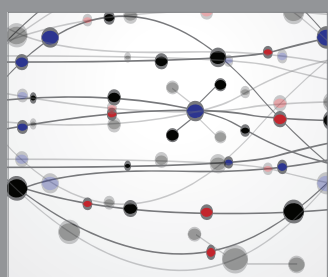

The Scientific World Journal

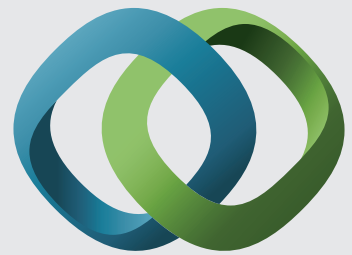

\section{Hindawi}

Submit your manuscripts at

http://www.hindawi.com
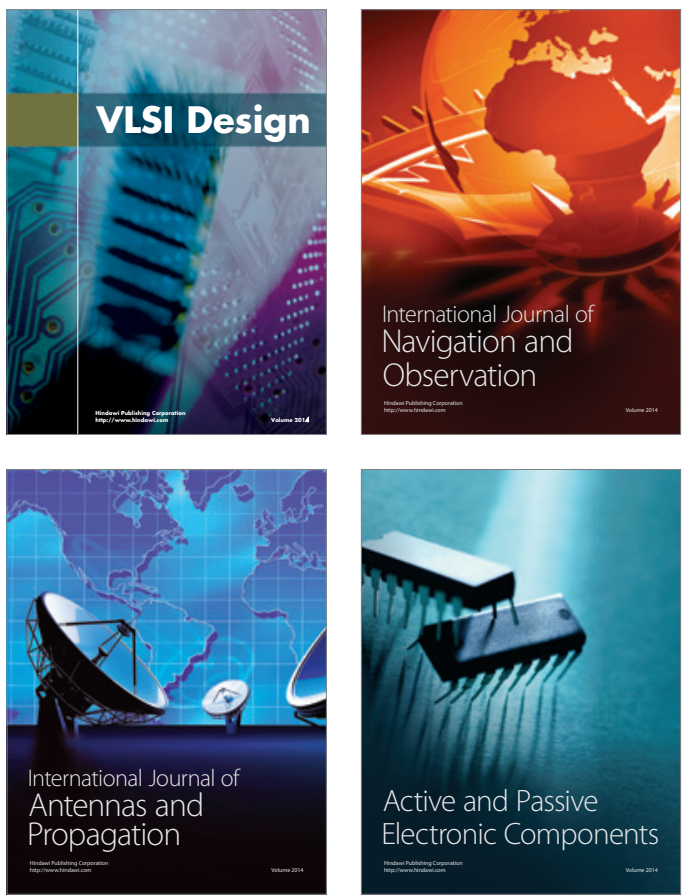
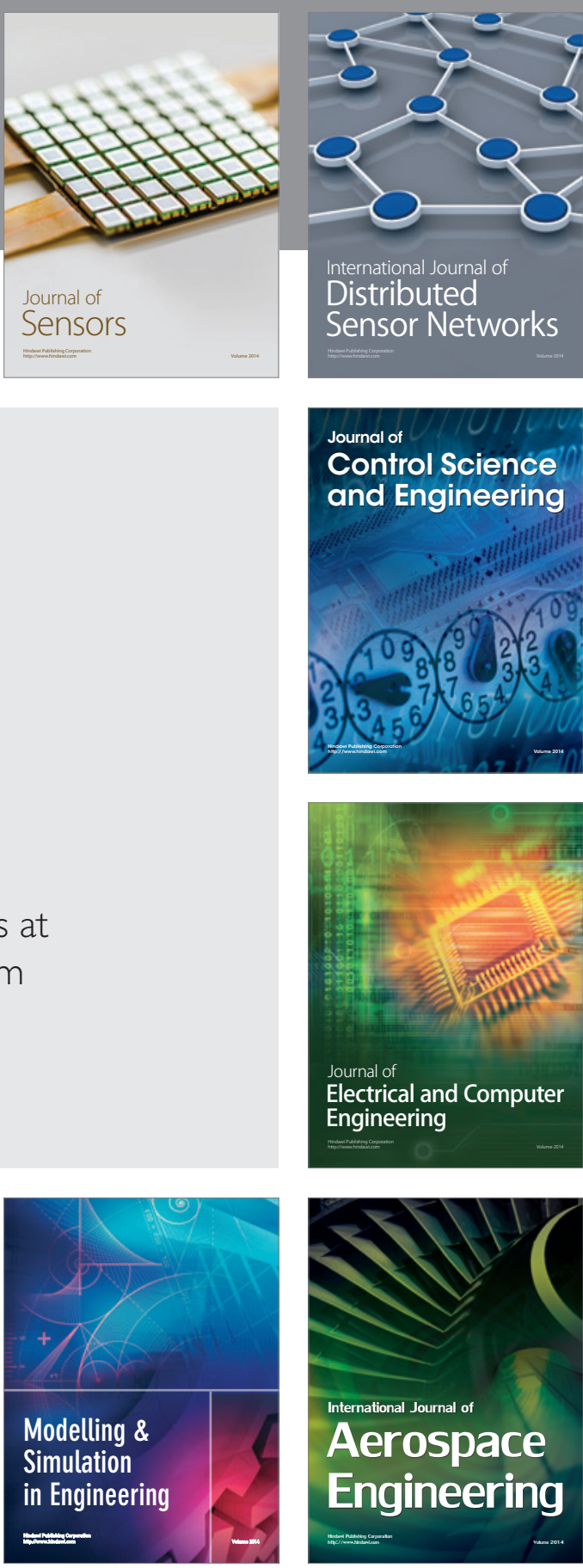

International Journal of

Distributed

Sensor Networks

Journal of

Control Science

and Engineering
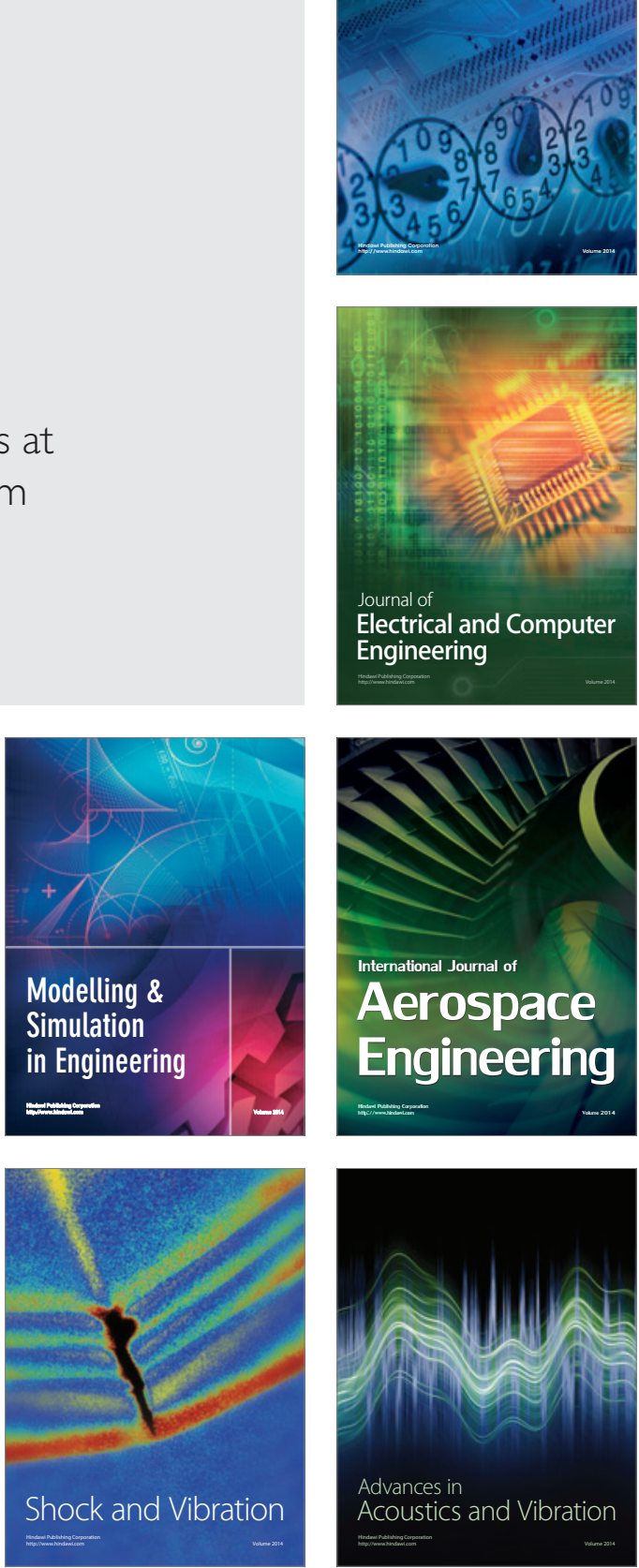